\title{
Emotions, Thoughts, Words
}

\section{Karine Kochunts}

Yerevan State University

\begin{abstract}
The subject of the present research is the subtle and intricate interconnection of human emotions, thoughts and words. As we know, human cognition is the ultimate form of reflecting the objective reality. Emotions reflect not the objective items and phenomena of the real world, but some subjective relationships in which these items exist. Thoughts and feelings in the model of the interaction of our consciousness with the world are the two means of its perception. Reflection has got two spheres: an intellectual and an affective, and the interaction of these two means that the rational and the emotional in the consciousness and thinking is manifested in the fact that man can emotionally experience what he/she reflects.
\end{abstract}

Key words: emotion, sensitive understanding, emotive, emotive seme, emotive meaning, loaded language.

\section{Introduction}

What are emotions? Are emotions characteristic of human beings only or can be traced in animals too?

Do emotions convey what people feel or what people think? Can a thought be devoid of any kind of emotion? Do emotions make people think or do thoughts make people feel?

Can people feel without thinking and think without feeling?

Are feelings and emotions the same? Is love a feeling or an emotion? Very superficial considerations may make us think that feelings should probably last longer than emotions, but the notion of relativity inevitably makes such judgments sound inaccurate. 


\section{Are Emotions and Feelings Different?}

Oxford Learner's Dictionary defines the word emotion as: "a strong feeling of any kind: love, joy, hate, fear, etc." The second definition is "excitement or disturbance of the feelings" (Oxford Advanced Learner's Dictionary of Current English, $7^{\text {th }}$ edition).

The word feeling is defined in the same source as "a thing that is felt through the mind or the senses". The second definition is "an idea or a belief that is difficult to define and not based entirely on reason". And the third definition, which is no less interesting and provocative, is "a person's emotions rather than her or his mind; a sensitive understanding".

The analysis of the definitions allows us to come to two thought-provoking conclusions: first, emotions are more likely to be defined as feelings than feelings as emotions. This nevertheless may give us the right to treat them as two nearly identical concepts, second, feelings are not mere emotions, they are also defined as ideas, beliefs, thoughts, consequently they should never be considered or examined separately from thoughts or as something opposed to the process of thinking. In fact emotions and thoughts often overlap: emotions trigger thoughts, thoughts trigger emotions.

Let us consider word-combinations with the word "emotion" taken from British National Corpus and try to track equivalence with their possible counterparts with the word "feeling":

I tell you, Dan, the people here are feeling every emotion in the book. Elation, fear, anxiety, everything.

"Uh, so I started thinking, Okay, what's a different emotion? Sadness... well, nobody wants to see a baby sad."

American Revolution of its inevitability. - Each piece of music is specific to an emotion and a character.

Paris on fire? I want to go all the way Take me to emotion...? 
Its purpose was to create the perfect killing machine. Human beings without emotion or fear or remorse.

Would you like to hear my voice?? Sprinkled with emotion?? And I thought, before I have this next baby...

Even the blurry or out of focus picture was better if it captured the emotion on the face.

Video game I think is probably the hardest thing to make.

If you want emotion, you need the human face, and in the world of film...

I keep my true feelings inside because most women can't handle the kind of emotion that I bring.

That's what enjoyment looks like on that face I like that emotion I keep emotion out of it.

His eyes burst with emotion and he suddenly took off stumbling after it...

- What's it called? - It's called... -?? Slow emotion?? Crickets chirping, dog barks in the distance, ominous music??

You can only apologize not to act! Repentance is a useless emotion.

I've known Jon long enough to see he isn't devoid of emotion.

Love is just a leftover emotion from our hairy ancestors. I mean, when your house is under constant attack... 
... percent of your decisions, based on logic, fact and reason, and allow emotion to be the secondary motivator.

If you're spending your life with someone, you can't rely on emotion.

It never has a chance for an honest emotion or thought ever to get through. And you're so filled with honest emotion.

But after that I just sort of leave it I find it hard to express emotion most of the time although I'm getting on top of that more happy now...

...you any harm, but my presence here... is motivated by man's purest emotion - - greed. Thank heaven for an honest man. Hmm. Gentlemen.

...Women seek intense and terrifying emotion... because they really enjoy it.

The above-adduced examples of various collocations with the word emotion come to prove that in the sematic comparison of the two words, emotion and feeling, the former allows wider use and flexibility, since in many of the collocations the word emotion could not be possibly replaced by the word feeling.For example, a leftover emotion, burst with emotion, capture the emotion, devoid of emotion, slow emotion, take me to emotion, etc. Thus, the word emotion better fits into the research field under study.

Karen Lawson from the University of Minnesota's Center for Spirituality \& Healing states that "thoughts and emotions have a profound effect on one another. Thoughts can trigger emotions (worrying about an upcoming job interview may cause fear) and also serve as an appraisal of that emotion ("this 
isn't a realistic fear"). In addition, how we attend to and appraise our lives has an effect on how we feel." (<https://www.takingcharge.csh.umn.edu $>$ )

Richard Davidson, professor of psychology and psychiatry at the University of Wisconsin-Madison, goes even further popularizing the idea that "one can learn happiness and compassion as skills just as one learns to play a musical instrument, or train in golf or tennis." (<https://www.stillnessspeaks.com $>$ )

\section{The Missing Unit in the Chain Emotions-Thoughts}

The chain emotion $\rightarrow$ thought or thought $\rightarrow$ emotion apparently lacks a unit, that is the way thoughts and emotions are actualized in speech. At this point it would not be out of place to remember Robert Frost's well-known quote: "Poetry is when an emotion has found its thought and the thought has found words." There is no doubt that thoughts and emotions must be given way and actualized through words, moreover, they must find the right words (apparently, there are also extralinguistic means of realizing emotions). Thus, the missing unit, even if not the closing one, is obviously the word.

Still, how frequently do we appear in situations when words are unable to express our thoughts and emotions, when they express them at least imprecisely, or we have a feeling that many emotions are simply beyond the words that we have or we know? In his book "Start with Why" Simon Sinek points out: "The part of the brain that controls our feelings has no capacity for language. It is this disconnection that makes putting our feelings into words so hard. We have trouble, for example, explaining why we married the person we married. We struggle to put into words the real reason why we love them, so we talk around it and we rationalize it. Rationally, we understand that our explanation isn't the real reason. It is how our loved ones make us feel, but those feelings are really hard to put into words..." Dr. Richard Restak in one of his outstanding books "The Naked Brain" suggests that "Gut decisions" feel right. There is no part of the stomach that controls decision-making, it all happens in the limbic brain. It is not an accident that we use that word "feel" to explain those decisions either" (Sinek 2009). Thus, the answer is - rather often. 
The linguistic expression of emotions has often been a target of research for linguists, psychologists and philosophers. From the second half of the XIX century the American linguistic school set a clear objective to trace relationships between emotions and language as means of their actualization. According to V.I. Shakhovski the essence of the linguistic approach to the study of emotions looks like this: there is the world (the object) and the human-being (the subject) capable of reflecting the world. The reflection of emotional states is localized in the semantic structure of corresponding words, the images of those objects to which they refer. This reflection is coded in the word with the specific components of its semantics which form the emotiveness of the word (Shakhovski 2008:3).

Thus, emotives are words which possess some kind of emotional component in their lexical meaning. The question is how the emotive meaning is referred to the denotational, connotational and lexical meanings of the word? Is this meaning inherent in the word or it may appear situationally or as a result of the speaker's intention? What is, for example, the difference in the emotiveness of the words want, wish, desire? Do we know the difference or do we feel it? It may seem that the tendency in the rank of emotiveness in these words is ascending: want is the least emotional, wish is moderately emotional and desire is the most emotional. The analysis of the emotiveness as the semantic component of words can become possible only when its tiniest meanings - the emotive semes - are present in the semantic system of a given language. Emotional semes reflect the subjective reality which is however objective for the word itself (Shakhovski 2008:74).

Let us turn to the dictionary definitions of the above-mentioned words proposed by Oxford Learner's Dictionary: want- $V$ to have a desire for something; to wish for something, wish $-v$ to want something that cannot now happen or that probably will not happen, desire $-v$ to wish for something, to want something; $n$ a strong wish to have or do something (Oxford Advanced Learner's Dictionary of Current English, $7^{\text {th }}$ edition). We see that the denotational meanings of the words do not seem to express any difference in the rank of emotiveness, moreover, they are interchangeably defined. Then 
how can we trace the subjective reality expressed by these words which is objective for the words themselves? What is the objective reality of words? To what extent can they be interchangeably used?

\section{The Subjective Reality Expressed by Words}

An attempt has been made to see the frequency of the use of these words in two hundred pages of S. Maugham's Sixty-Five Short Stories. The results are as follows: want -201, wish -25, desire-11.

Thus, if they could be interchangeably used, the difference in number would not be so dramatic. The most neutral emotive seme want is used nearly eight times as much as the more emotive seme wish and twenty times as much as its most emotive counterpart desire.

A little native girl brought them a dish of Hamburger steak, and after a while the trader came up to see that they had everything they wanted. (p. 116)

When people come and ask if I can rent them a room all I want to know is if they've the money to pay for it. And she paid me for hers a week in advance. (p. 406)

I want to put in her heart the passionate desire to be punished so that at the end, even if I offered to let her go, she would refuse. I want her to feel that the bitter punishment of prison is the thank-offering that she places at the feet of our Blessed Lord, who gave his life for her.'(p. 621)

In the first two sentences above the author chooses to use the word want, the most neutral of the three, as the context does not seem to prompt a strong emotion. In the third sentence we see want used twice and one use of desire. The noun desire is preceded by the adjective passionate, which multiplies the rank of emotiveness, thus justifying the use of the word, but then a question is 
bound to arise: does the word want not possess the same amount of emotion in the given context?

'You know there's nothing in the world I want more than your happiness, Isabel.'(p. 96)

There is apparently so much emotion in the context of this sentence that again we may question the appropriateness of the use of the word want.

'Do you wish me to give her that message, Edward? Oh, I can't. It's terrible. It's never dawned on her for a moment that you don't want to marry her. She loves you. How can I inflict such a mortification on her?'(p. 92)

What possibly makes the author choose the word wish and not want in the sentences like this? Had the author used want, it would most likely diminish the emotional outburst of the character?

In long, idle talks he had inflamed their hearts with the desire for gain. (p. 208)

A tremendous desire seized him to humiliate that gross and cruel man; he would give anything in the world to see him in the dust, suffering as much as he had made others suffer. (p. 204)

In both sentences we see a strong emotion expressed by the word desire: in the first case there is a desire to gain, which is almost always strong and deep, in the second case the word is preceded by a strong attribute (tremendous desire).

The analysis of a number of instances where the three words are used by the author allows believing that emotional communication realizes the emotive components of the lexical meaning in the form of the emotive meaning, 
connotation or emotive potential. At the same time the emotional potential of the word may be inherent and acquired or situational, objective and subjective.

Thus, it can be rightfully concluded that "words carry with them something more than a simple description of a concept or an action. They have a "magnetic" effect, an imperative force, a tendency to influence the interlocutor's decisions" (<https://en.wikipedia.org/wiki/Loaded_language >).

\section{Conclusion}

The research allows us to believe that human emotions, thoughts and words cannot be or appear isolated, they are always and by all means interconnected and often trigger or influence each other. The chain emotions $\rightarrow$ thoughts $\rightarrow$ words is represented in the order in which they appear from the perspective of human cognition, which means that the emotional reflection of the world triggers the rational reflection which gets actualized through words. Still, because emotions, thoughts and words can sometimes overlap, a thought can precede an emotion, or a word may trigger a thought or/and an emotion.

\section{References:}

1. Davidson, J.R.; Begley Sh. (2004) The Emotional Life of Your Brain: How Its Unique Patterns Affect the Way You Think, Feel, and Live - and How You Can Change Them. UK: Hudson Street Press.

2. Hornby, A.S. and Wehmeier, S. (2005) Oxford Advanced Learner's Dictionary of Current English, $7^{\text {th }}$ ed. Oxford: OUP.

3. Maslow, A. (2011) Hierarchy of Needs: a Theory of Human Motivation. New York: Public Affairs (Perseuus Book Group).

4. Restak, R. (2007) The Naked Brain: How the Emerging Neurosociety is Changing How We Live, Work, and Love. New York: Broadway Books.

5. Shakhovski, V.I. (2008) Lingvisticheskaya teoriya emociy. M.: Gnozis.

6. Sinek, S. (2009) Start with Why: How Great Leaders Inspire Everyone to Take Action. New York: Penguin Group. 
7. Taking Care of Your Health and Wellbeing. Available at: $<$ https://www.takingcharge.csh.umn.edu> [Accessed January 2019].

8. Zimmerman, M. (2017) Self-Knowledge Learning Needs vs. SelfActualization Skills. // How to Make the World a Better Place, Chapter 8. Canada: Vintage.

\section{Sources of Data:}

1. British National Corpus. Available at: <https://www.englishcorpora.org/bnc/> [Accessed December 2018].

2. Maugham, W.S. (1988) Sixty-Five Short Stories. London: Octopus Books Limited.

\section{Znujqtip, unpten, puntep}

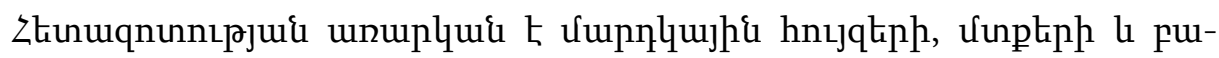

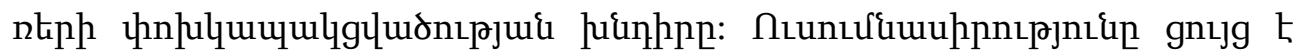

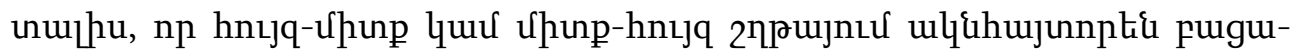

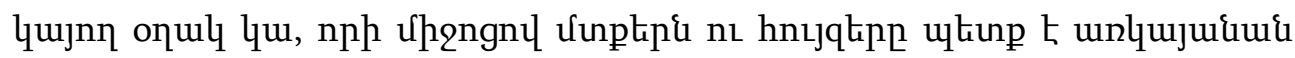

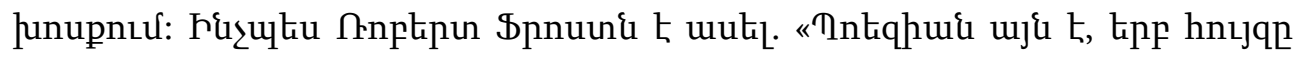

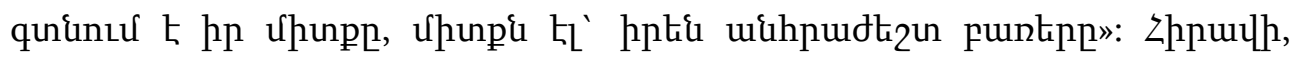

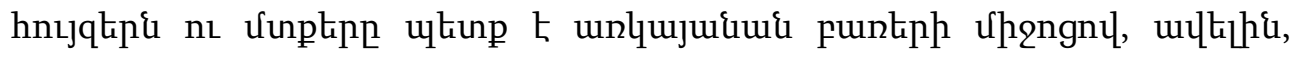

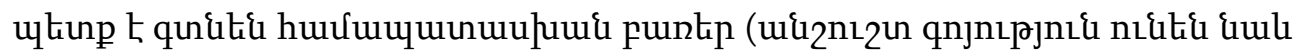

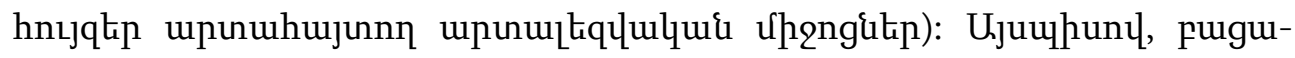

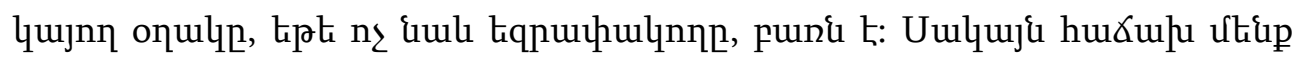

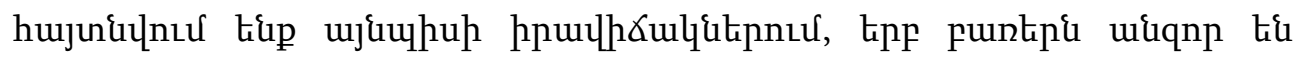

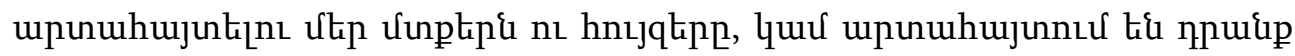

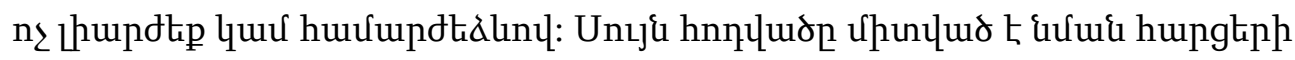

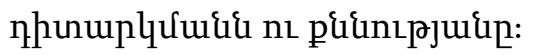

